Tarih Kültür ve Sanat Araştırmaları Dergisi

Revue des Recherches en Histoire Culture et Art مجلة البحوث التاريخية و الثقافية والفنية
Vol. 7, No. 4, November 2018 Copyright (C) Karabuk University http://kutaksam.karabuk.edu.tr

\title{
DOI: 10.7596/taksad.v7i4.1805
}

Citation: Galimova, G., Panchenko, O., Mukhametzyanova, F., \& Mendibaev, N. (2018). Effects of New Economic Reality on Social Changes: A Cross-Cultural Analysis. Journal of History Culture and Art Research, 7(4), 47-54. doi:http://dx.doi.org/10.7596/taksad.v7i4.1805

\section{Effects of New Economic Reality on Social Changes: A Cross-Cultural Analysis}

\author{
Gulnaz Galimova ${ }^{1}$, Olga Panchenko², \\ Flera Mukhametzyanova ${ }^{3}$, Nuratbek Mendibaev ${ }^{4}$
}

\begin{abstract}
The paper presents a cross-cultural analysis of the life quality of the rural population on the materials from various sources in Russia and Kyrgyzstan. A brief review of the research field, foreign and domestic works is presented. The problem potential of the life quality of the rural population is revealed based on the materials of our empirical research. Methods of research were a mass survey (Republic of Kyrgyzstan), analysis of statistical data for the Russian Federation and the Republic of Kyrgyzstan. The authors made a conclusion about the predominantly negative influence of modern socio-economic processes on the life quality of the rural population. The similarity of situations in both regions is ascertained and the necessity of optimizing the policy pursued with respect to rural areas is justified.
\end{abstract}

Keywords: Rural sociology, social problems, rural way of life, life quality

\footnotetext{
1 Student, Institute of International Relations, Kazan Federal University (Russia). E-mail: Gulnaz_1996_2010@mail.ru

$2 \mathrm{PhD}$ in Sociology, associate professor, Department of world cultural heritage, Institute of International Relations, Kazan Federal University (Russia). E-mail: global@ores.su

${ }^{3}$ Doctor of Education, professor, Department of world cultural heritage, Institute of International Relations, Kazan Federal University (Russia). E-mail: FGMuhametzyanova@kpfu.ru

4 Doctor of Sociological Sciences, professor, Kyrgyz Islamic University (Republic of Kyrgyzstan). E-mail: global@ores.su
} 


\section{INTRODUCTION}

Liberalization of social and economic life contributed to profound changes in the life of rural society and gave a new direction to creative practices. The transition period is characterized by a deterioration in the socio-economic status of rural communities, rising unemployment and increasing poverty, and a new social stratification. These trends are typical for the entire post-Soviet space, including Russia and the countries of Central Asia. The paper presents a cross-cultural analysis of changes in the rural image and life quality over the past 10-15 years based on the example of the Russian Federation (hereinafter Russia) and the Republic of Kyrgyzstan (hereinafter - Kyrgyzstan). The study of transformation processes affecting the quality and standard of living of rural communities becomes an urgent need with the aim of developing adequate forms of rural management, new directions and methods for improving social and economic policies. This is due to a number of circumstances.

Firstly, the rural areas are the main place to live and work of a significant majority of Russians and Kyrgyz. In Kyrgyzstan, the rural population is 4135.7 thousand people (53\%) [6]. In Russia, the rural population is also very large and amounts to 37.6 million people (36\%) [7]. Accordingly, the rural areas largely determine the strategy for the further development of these countries. Secondly, a significant amount of Russia's gross domestic product and the bulk of Kyrgyzstan are formed through agricultural labor of the agro-industrial sector, in Kyrgyzstan it is a budget-forming one. In Russia, increased attention to agricultural complex necessitates the improvement of farming methods and, accordingly, the development of appropriate measures to encourage the production activity of the villagers in recent years. Thirdly, it is difficult for Russia as an industrial and agrarian country with a high agrarian potential, and for Kyrgyzstan as an agrarian country, to develop their economy without a general rise in agriculture, and without reconstruction of the social infrastructure of their rural areas. Fourth, it is known that the state of society is measured by the life quality of a person. Accordingly, the essence of reforms carried out in these countries should be to improve the life quality of people and social communities.

Studies show that neither in Russia nor in Kyrgyzstan they have objective conditions to complete formation of the social structure of the market type until now; their agriculture and the agricultural complex have a transitional character. At the same time, it is necessary to note the positive tendencies of recent years, namely, the direction of state reforms concerning the social infrastructure of the rural areas, which applies equally to both Russia and Kyrgyzstan. Such a turn is due to the need to take into account the social and mental, traditional prerequisites in the functioning of the inhabitants of rural areas and their communities. Finally, after long liberal-reformist years, the attention of the scientific community and the leadership of the countries is directed towards the rural areas as a potential for the development of the state $[8, p .77]$. This is also related to the development of food security, which is particularly characteristic of modern Russia. Thus, the study on the degree of stability of the rural areas to the ongoing reforms, the available social reserves are today an important area of sociological and interdisciplinary research.

\section{METHODS}

The study of social changes in the rural areas takes place at the junction of two lines in the sociology of the middle level: the sociology of the rural areas and the sociology of social change. The rural areas are a specific settlement category, which was applied by sociologists of recent decades.

The theoretical analysis carried out in the field of the life quality of the rural population showed that the studies of foreign and domestic authors are based on various aspects of this topic. The researches of foreign authors are focused to a greater extent on the health of rural population as a component of the life quality: the works are devoted to revealing the influence of the rural way of life on the mental state of 
the inhabitants [11]; development of health-saving technologies in rural areas [12]; epidemiological sustainability of residents of rural communities [14]; and peculiarities of the aging process in rural communities [15]. The analysis showed that the most obvious in these studies is the medical aspect. Only in some works the life quality is treated as a complex concept [13], or a cross-cultural section of the problem is carried out [10].

A somewhat different aspect of research is seen in the domestic scientific literature. First of all, this is a socio-economic aspect with the identification of the main socio-demographic trends. Migration and urbanization, lowering the economic level in the rural areas, and the impact of new economic processes on the deterioration of the life quality of rural residents are being problematized [1-3, 5]. Upon that, the life quality, on the contrary, is more often treated as an integral concept which includes components of health, safety, living standards and so on $[4,9]$.

Our study is based on the use of an integrated methodology. On the one hand, the potential of systemic and anthroposocietal approaches to the study of rural areas as a systemic formation characterized with integrity and interconnection elements is used. On the other hand, individual components of the vitalist sociology reflecting the functioning of rural communities as a life system are applied. The development of the rural areas is conditioned by the resources of the vital forces, which are the traditionality and innovative nature of the rural areas. The purpose of the work is to study the living standards of the rural population and the social factors of its development, the dynamics of the standard of living in a transition to a market economy.

The empirical base was the results of studies conducted in Kyrgyzstan in 2013-2014 (method - a mass questionnaire survey, $\mathrm{N}=1200$, in-depth interviews $\mathrm{N}=164$ ) ${ }^{5}$ analysis of documentary sources (data of official statistics of Russia and Kyrgyzstan), secondary analysis of research in Russia. The method of comparative analysis was also applied. The procedure for the study involved several stages:

Stage 1 - generalization of available theoretical material and substantiation of the methodological base of the research;

Stage 2 - analysis of data obtained in the course of field survey conducted in 2012 in Kyrgyzstan;

Stage 3 - analysis of statistical data for Russia and Kyrgyzstan;

Stage 4 - comparative-analytical.

\section{RESULTS}

The transition of Russia and Kyrgyzstan to market relations, formation of the first degree of those relations led to a decline in living standards, distrust to the future and intensification of the tension factor. Unemployment, rising prices, and dissatisfaction with social needs are all the result of a weak social adaptation level of the rural population to the new market conditions, and a decline in the people's standard of living. One of the main directions of the state policy in the modern Kyrgyzstan is the social sphere, and $60 \%$ of budget means are spent on social needs. The impact of the changes in life on the behavioral and mental aspects of human activity is one of the important problems of today. Thus, according to the results of the analysis of author's researches, the majority (46\%) of the respondents in rural Kyrgyzstan live in rural areas for more than 25 years, or from 16 to 25 years (30\%), that is, they are

\footnotetext{
${ }^{5}$ The study was conducted by the author in 2013 among 1200 respondents, who were residents of rural settlements of the Kyrgyz Republic. Residents of 16 districts and 7 regions of the Republic were interviewed. The distribution of the respondents by their gender was the following: men - 574 people, women - 626 people. Fetch error was $5 \%$.
} 
aborigines, or old residents; $17 \%$ live $5-15$ years, $7 \%$ - up to 5 years, that is, in fact they are migrants in the recent past from another locality. A high proportion of the indigenous inhabitants of the rural areas may testify to that their population is being updated poorly: young people do not come to the countryside very actively because the possibilities for applying their labor here are extremely limited.

The question "Why do you prefer to live in the countryside?" had the following answers: $49 \%$ of respondents answered that they have their own land plot, their own house, are engaged in subsidiary farming, provide themselves with natural food and other goods. About half - $42 \%$ - noted that the main reason is living together with their parents, relatives and the desire to be with their fellow villagers, which is a special way of life. Such traits are characteristic of people aged 41 to 50 years who have secondary vocational education and engaged in peasant or farming. $25 \%$ of the villagers prefer that they have such features of life in the countryside available as clean mountain air, cool wind, clear spring waters, a favorable climate, beautiful nature, romance, and $28 \%$ of respondents believe that living in the rural areas today is economically profitable, since it does not require such large expenditures as in urban areas. Among the respondents, $18 \%$ said that it is in the rural areas that the traditions and customs of their ancestors are preserved from time immemorial, the idea of unity is developing, the rural areas are a small motherland and the patriotic feeling of people is enshrined there (Table 1).

Table 1. The motivation of villagers to live in rural areas (Distribution by the question: "Why do you prefer to live in the countryside?"), 1200 people answered, in \% to the total of respondents

\begin{tabular}{|l|l|}
\hline Variants of answers & Response rate, $\%$ \\
\hline Less money spent & 28.3 \\
\hline Good climate and environmental conditions & 24.9 \\
\hline Interesting work & 9.2 \\
\hline Traditional features & 17.4 \\
\hline I have a property & 49.4 \\
\hline I live with my parents & 42.1 \\
\hline Here is my small motherland & 18.4 \\
\hline Other & 0.7 \\
\hline Total respondents & 100.0 \\
\hline
\end{tabular}

In the market conditions, social changes in Kyrgyzstan are largely due to new forms of management. As the results of the research show, the majority of respondents (46\%) answered the question: "What kind of management in the rural areas do you consider the most reliable?" so that they believe in the future of private economy as the most acceptable form of free economic management. By age, these were the people aged 31-40 (59\%). The fifth part of respondents - $20 \%$ - considered a family lease to be the most reliable form of business, of which 51-60 years old people (24\%) believe in the future of this form. The development of market relations in the Kyrgyz rural areas largely depends on the rational organization of the farm. The above problems have their own objective and subjective reasons. Therefore, the liquidation 
of many state-owned enterprises, organizations and institutions leads to unemployment, deterioration in the standard of living of the entire population.

Thus, according to official statistics, the level of poverty in Kyrgyzstan remains high. At the same time, it is the highest in rural settlements (see Table 2).

Table 2. Level of poverty of rural and urban population of Kyrgyzstan, \% of total population (dynamics by years)

\begin{tabular}{|c|c|c|c|c|c|c|}
\hline \multirow[t]{2}{*}{ Years } & \multicolumn{2}{|l|}{ Total } & \multicolumn{2}{|c|}{ Countryside } & \multicolumn{2}{|c|}{ Urban Area } \\
\hline & very poor & poor & very poor & poor & very poor & poor \\
\hline 2009 & 6.6 & 35 & 8.5 & 41.7 & 3.2 & 23. 2 \\
\hline 2011 & 3.1 & 31.7 & 3.3 & 37.1 & 2.7 & 21.9 \\
\hline 2013 & 5.3 & 33.7 & 6 & 39.5 & 4.2 & 23. 6 \\
\hline 2015 & 4.5 & 36.8 & 5.7 & 40.4 & 2.6 & 30.7 \\
\hline
\end{tabular}

In 2016, the poverty level as a whole in the republic was $37 \%$ and remained at the same level in relation to the previous year. At the same time, in urban settlements the level of poverty decreased by $7 \%$, and in rural areas, by contrast, increased by $2 \%$ [6].

According to statistics, the main source of household income is remuneration of labor and income from entrepreneurial activities, which is $62 \%$ of household income. Other types of income include social transfers (14\%), proceeds from sales of agricultural products, feed, livestock (18\%), property income (1\%), and other types of income (5\%) [6]. As can be seen from the data given, wages are preferential, but not the main source of income for citizens; increasing importance is attached to the maintenance of a personal (subsidiary) farm. The established level of salaries is not sufficient to ensure a decent standard of living for the villagers, especially given the sector-specific nature of salaries.

Thus, the dynamics of the life quality and level of the villagers in Kyrgyzstan testify to the under-utilized potential in regulating the socio-economic component of rural life. Next, we should refer to the data of Russian realities.

According to official statistics, the level of employment in rural areas of the Russian Federation has been steadily declining over the past few years. So, in 2014 it decreased by $2 \%$ compared to 2013, in 2015 - by another $2 \%$ [7]. This allows us to talk about the reduction of the labor potential of the rural areas and the growth of negative trends in the rural community and its disintegration. This is also manifested in the fact that the majority of young people rush into the city for work, leaving agrarian production for the older generation. The trends are absolutely similar to Kyrgyzstan. Similarly, rural residents in Russia continue to maintain their own subsistence economy - $100 \%$ of villagers in the republic have their own farm, about half of them live solely at the expense of income from subsistence farming.

\section{DISCUSSION}

The analysis showed that in modern rural communities there are processes of social differentiation for a number of reasons. Inequality in income naturally causes inequality in access to goods. Thus, the level of 
food consumption among rural residents remains very low, in fact working family members restrict themselves and their loved ones in consuming the necessary food, as well as purchasing durable goods, obtaining necessary and vital benefits and services such as education, medical care, disease prevention and health improvement, travel as a form of recreation. At the same time, only half of the villagers are satisfied with their income level, which indicates a high level of subjectively perceived poverty of the population.

Analysis of research results by regions as socio-cultural spaces showed that social changes in the rural life quality have a negative vector. The disunity of the rural community on the basis of ongoing liberal reforms does not contribute to the preservation of the identity of the Russian and Kyrgyz rural areas. In both regions there are processes of social differentiation. As a consequence, the violation of the societal integrity of rural areas will undoubtedly have an extremely negative impact on the trajectory of rural development in the short term and requires timely solutions.

\section{CONCLUSION}

Thus, this fact indicates that the adaptation potential of the rural population in the new economic reality is not high. The rural population is looking for opportunities to apply their labor outside the place of their residence, what is due to the conjuncture of the rural labor market, where the range of opportunities for self-realization of villagers, especially young people, is limited.

\section{ACKNOWLEDGMENTS}

The work is carried out according to the Russian Government Program of Competitive Growth of Kazan Federal University.

\section{FOOTNOTES}

[1] Voronin, B. A., Mayzel, S. G., Voronina, Y. V., Fateeva, N. B., \& Dolgopolova, A. A. (2016). Life quality in rural areas: status, ways to improve. Agricultural Education and Science, 3, 4-11. (In Russian)

[2] Gann, G. V. (2012). Life quality of the rural population. EKO, 10, 141-148. (In Russian)

[3] Kurkina, M. P. (2012). Reproduction of population and life quality in rural areas. NIC Sociosfera, Conference collections SIC, 11, 65-69. (In Russian)

[4] Mendibayev, N. (2014). Selo as a societal integrity in a transformed society. Bishkek. (In Russian)

[5] Molchanova, A. V., \& Abryandina, V. V. (2016). Actual problems of economic sustainability of rural areas. Economics, management, and labor in agriculture, 1(26), 103-106. (In Russian)

[6] National Statistical Committee of the Kyrgyz Republic (Official website). URL: http://www.stat.kg/ru/statistics/naselenie/ (accessed on 19.05.2018)

[7] Rosstat (Official website). URL:

http://www.gks.ru/wps/wcm/connect/rosstat_main/rosstat/ru/statistics/population/demography/\# (accessed on 16.04.2018) (In Russian)

[8] Podgorbunskikh, P. E., \& Golovin, S. G. (2012). Algorithm for monitoring a sustainable development in rural territories. Agrarian bulletin of the Urals, 5(97), 79-83. (In Russian) 
[9] Khudyakov, S. I. (2009). A new role of culture in the transformed society: from an economycentrism to a culture-centrism. Social and humanitarian knowledge, 2; 58-68. (In Russian)

[10] Barua, A., Mangesh, R., Harsha Kumar, H. N., \& Mathew, S. (2007). A cross-sectional study on life quality in geriatric population. Indian Journal of Community Med, 32(2), 146-147.

[11] Huppert, F. A., \& Whittington, J. E. (2003). Evidence for the independence of positive and negative well-being: Implications for life quality assessment. British Journal of Health Psychology, 8, 107122.

[12] Hartley, D. (2004). Rural Health Disparities, Population Health, and Rural Culture. American Journal of Public Health, 94(10), 89-93.

[13] Mudey, A., Ambekar, S., Goyal, R. C., Agarekar, S., \& Wagh, V. V. (2011). Assessment of life quality among rural and urban elderly population of Wardha District, Maharashtra, India. Studies on ethnomedicine, 5(2), 89-93. DOI: https://doi.org/10.1080/09735070.2011.1188639494

[14] Mahadeva, S., Yadav, H., Rampal, S., \& Goh, K. L. (2010). Risk Factors Associated with Dyspepsia in a Rural Asian Population and Its Impact on Quality of Life. The American Journal of Gastroenterology, 105, 904-912. DOI: 10.1038/ajg.2010.26

[15] Mwanyangala, M. A., Mayombana, C., Urassa, H., Charles, J., Mahutanga, C., Abdullah, S., \& Nathan, R. (2010). Health status and life quality among older adults in rural Tanzania. Global Health Action, 3, 36-45.

\section{REFERENCES}

Barua, A.; Mangesh, R.; Harsha Kumar, H. N. \& Mathew, S. (2007). A cross-sectional study on life quality in geriatric population. Indian Journal of Community Med, 32(2), 146-147.

Gann, G. V. (2012). Life quality of the rural population. EKO, 10, 141-148. (In Russian)

Hartley, D. (2004). Rural Health Disparities, Population Health, and Rural Culture. American Journal of Public Health, 94(10), 89-93.

Huppert, F. A. \& Whittington, J. E. (2003). Evidence for the independence of positive and negative wellbeing: Implications for life quality assessment. British Journal of Health Psychology, 8, 107-122.

Khudyakov, S. I. (2009). A new role of culture in the transformed society: from an economy-centrism to a culture-centrism. Social and humanitarian knowledge, 2; 58-68. (In Russian)

Kurkina, M. P. (2012). Reproduction of population and life quality in rural areas. NIC Sociosfera, Conference collections SIC, 11, 65-69. (In Russian)

Mahadeva, S.; Yadav, H.; Rampal, S. \& Goh, K. L. (2010). Risk Factors Associated with Dyspepsia in a Rural Asian Population and Its Impact on Quality of Life. The American Journal of Gastroenterology, 105, 904912. DOI: 10.1038/ajg.2010.26

Mendibayev, N. (2014). Selo as a societal integrity in a transformed society. Bishkek. (In Russian)

Molchanova, A. V. \& Abryandina, V. V. (2016). Actual problems of economic sustainability of rural areas. Economics, management, and labor in agriculture, 1(26), 103-106. (In Russian) 
Mudey, A.; Ambekar, S.; Goyal, R. C.; Agarekar, S. \& Wagh, V. V. (2011). Assessment of life quality among rural and urban elderly population of Wardha District, Maharashtra, India. Studies on ethno-medicine, 5(2), 89-93. DOI: https://doi.org/10.1080/09735070.2011.11886394

Mwanyangala, M. A.; Mayombana, C.; Urassa, H.; Charles, J.; Mahutanga, C.; Abdullah, S. \& Nathan, R. (2010). Health status and life quality among older adults in rural Tanzania. Global Health Action, 3, 36-45.

National Statistical Committee of the Kyrgyz Republic (Official website). URL:

http://www.stat.kg/ru/statistics/naselenie/ (accessed on 19.05.2018)

Podgorbunskikh, P. E. \& Golovin, S. G. (2012). Algorithm for monitoring a sustainable development in rural territories. Agrarian bulletin of the Urals, 5(97), 79-83. (In Russian)

Rosstat (Official website). URL:

http://www.gks.ru/wps/wcm/connect/rosstat_main/rosstat/ru/statistics/population/demography/\# (accessed on 16.04.2018) (In Russian)

Voronin, B. A.; Mayzel, S. G.; Voronina, Y. V.; Fateeva, N. B. \& Dolgopolova, A. A. (2016). Life quality in rural areas: status, ways to improve. Agricultural Education and Science, 3, 4-11. (In Russian) 